\title{
A STUDY OF INTESTINAL PARASITES IN CHILDREN OF AN URBAN REGION WITH EXCELLENT SANITARY CONDITION REVEALS HIGH OCCURRENCE OF
}

\section{Blastocystis spp}

Bianca Martins dos Santos ${ }^{1,2}$, Felipe Augusto Soares ${ }^{1,2}$, Stefany Laryssa Rosa ${ }^{1,2}$, Denise da Conceição Ferreira Gomes ${ }^{2}$, Celso Tetsuo Nagase Suzuki ${ }^{2,4}$, Walter Bertequini Nagata ${ }^{3}$, Silvia Helena Venturoli Perri ${ }^{3}$, Fabio Franco Teixeira de Freitas 4 , Katia Denise Saraiva Bresciani ${ }^{3}$, Alexandre Xavier Falcão ${ }^{2}$ and Jancarlo Ferreira Gomes ${ }^{1,2}$

\section{ABSTRACT}

\begin{abstract}
Intestinal parasites are among the major causative agents of diseases that affect animals and humans, especially children. In view of this, the current study evaluated the occurrence of these parasitic agents in 737 children in an urban region with excellent sanitation condition of the city of Pedreira, São Paulo, Brazil. Fecal samples from the children were processed with the use of a technique of high diagnostic efficiency (TF-Test ${ }^{\mathbb{1}}$ ). The diagnosis of these samples resulted in the detection of 557 parasitic structures among eleven genera of parasites, and of $46.4 \%$ (342/737) infected children. Blastocystis spp. was found in 69.6\% (238/342) of the positive samples and the monoparasitism was accompanied by symptoms in 44 children. Furthermore, $67.8 \%(232 / 342)$ of the infected children had close contact with pets, suggesting a possible zoonotic transmission. Lastly, this study allowed to perform health education to the children, aiming the reduction of new intestinal parasitic infections.
\end{abstract}

KEY WORDS: Children; diagnosis; intestinal parasites; infection; public health.

\section{INTRODUCTION}

Intestinal parasites are among the major causes of disease in humans (Brooker, 2010; Carvalho et al., 2012). The high prevalence of these infections is a serious public health problem, particularly in developing countries from tropical, subtropical and equatorial climate regions, where the socioeconomic development is deficient, in combination with poor sanitation and low population economic power (Menezes et al., 2008; Melo et al., 2010; Barreto

\footnotetext{
1. Faculty of Medical Sciences, University of Campinas (UNICAMP), Campinas, São Paulo, Brazil.

2. Laboratory of Image Data Science, Institute of Computing, UNICAMP, Campinas, São Paulo, Brazil.

3. São Paulo State University (UNESP), School of Veterinary Medicine, Araçatuba, São Paulo, Brazil.

4. ImmunoCamp Science and Technology

Corresponding author: Bianca Martins dos Santos. E-mail: biancamsantos@yahoo.com.br
} 
et al., 2010; Brooker, 2010). Enteroparasitism is frequently associated with malnutrition issues, anemia, growth and cognitive disorders, irritability and increased susceptibility to other infections, especially during childhood (Biscegli et al., 2009; Fonseca et al., 2014; Rebolla et al., 2016).

A study in Nicaragua, with 961 children, showed that poor nutrition resulting from enteroparasites infection can be an important factor in the occurrence of organic development failure, such as physical and mental disorders (Oberhelman et al., 1998). It is worth mentioning that the children population is more susceptible to parasitic diseases due to the lack of knowledge in personal and food hygiene and immunological immaturity (Lawton \& Cooper, 1989; Biscegli et al., 2009; Gonzáles-Moreno et al., 2010; Belo et at., 2012). In Brazil, it is estimated that more than half of the children with up to eight years old may have infections by at least one species of enteric parasite, and that the prevalence rate may vary according to region (Belo et al., 2012; Pedraza et al., 2014; Carvalho et al., 2015; Rebolla et al., 2016). Epidemiological studies conducted in several regions of the country found prevalence indexes that ranged from $31 \%$ to $67 \%$ of enteroparasites infection in the children population (Barreto et al., 2010; Belo et al., 2012; Pedraza et al., 2014; Rebolla et al., 2016).

Although effectively recognized as the most frequent protozoa in humans, especially in children, Blastocystis spp. is uncommonly found in laboratory diagnosis. Many reports show the occurrence of four subtypes (e.g., ST1, ST2, ST3 and ST6) of this parasite in humans varying with the studied region (Laodim et al., 2012; Carvalho et al., 2012; Carvalho et al., 2015; Melo et al., 2017). Actually, there are 17 subtypes (ST1 to ST17) of Blastocystis spp. isolated from mammals and birds, nine (ST1 to ST9) have been found in humans with predominance of subtypes 1-4 (Stensvold \& Clark, 2016; Melo et al., 2017). Although this parasite has been receiving more attention in the last three decades (Tan et al., 2010; Melo et al., 2017), the detection of this intestinal parasite may have been underestimated. It may be a result of improper use of parasitological techniques in epidemiological surveys and laboratory routines as well as due to the lack of professional's microscopy ability to identify this parasite structure eliminated in the stool, which may vary without restriction in shape and size (Garcia, 2009; Carvalho et al., 2015; Rebolla et al., 2016).

Differently from studies carried out in regions with poor sanitary conditions, this study aimed an epidemiological survey of enteroparasites in a children population from an urban region with excellent sanitation condition in the city of Pedreira, State of São Paulo, Brazil. The diagnostic technique used was a parasitological one established in the literature as of high sensitivity - TFTest (Three Fecal Test), which, as in other studies, made it possible to estimate with high efficiency the infected population (Gomes et al., 2004; Carvalho et al., 2015; Coelho et al., 2015; Rebolla et al., 2016; Inácio et al., 2016). 


\section{MATERIAL AND METHODS}

\section{Subjects and Study Area}

This study was conducted with the participation of 737 school children of both genders, aged five to eight years old, all enrolled in the municipal school and residents of the city of Pedreira, SP, Brazil. In accordance with the Brazilian Institute of Geography and Statistics (acronym in portuguese, IBGE), 2013 census, this city had an estimated population of 44,509 inhabitants; located in latitude $22^{\circ} 44^{\prime} 31^{\prime \prime}$ southern and longitude $46^{\circ} 54^{\prime} 05^{\prime \prime}$ west, with an altitude of 584 meters above the sea (Figure 1). According to participant's convenience, a random sampling was carried out. An authorization consent form with a questionaire was required to be signed by the children's parents as to obtain information, such as: sanitary condition of residence; interaction with pets; clinical symptomatology days prior to this study and elimination of some kind of unusual material in the child stool before the current study. In addition, specific training was held in order to convey to children and their parent's health education as to achieve control and reduction of new intestinal parasitic infections.

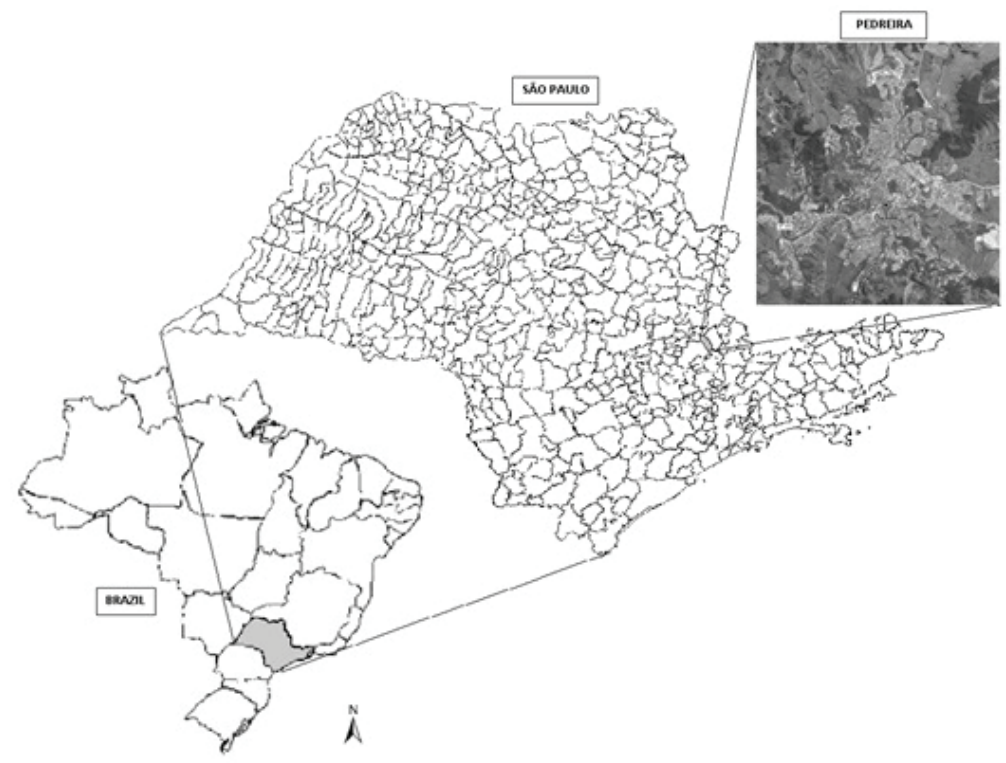

Figure 1. Localization of the city of Pedreira, State of São Paulo, Brazil. 


\section{Sample Collection and Parasitological Technique}

Through training and a simplified illustrative text, the parents of each child were told to collect at home three stool samples every other day (day in, day out), according to the TF-Test technique (BioBrasil Biotecnologia $\bigcirc$ ) and operating protocol of the parasitological kit manufacturer. About $1.0 \mathrm{~g}$ of stool specimen was collected with a scoop connected to the cap, from each of three vials (collectors) containing individually $5 \mathrm{~mL}$ of neutral preservation solution, buffered formalin $(7.5 \%)(\mathrm{pH}=7.2)$. Three specimens of each participant were obtained on alternate days, and then taken to be processed by centrifugationsedimentation method and microscopic analyzed. In the laboratory, $3 \mathrm{~mL}$ ethylacetate and a drop of detergent were added to each vial. After homogenization, all the vials were coupled to a double-filtration system attached to a conical centrifuge tube and submitted to a 1-min centrifugation (500 g). The centrifuge tube was then detached from the system, the supernatant was discarded, 10 drops of saline were added to the sediment, and one drop of the sediment suspension was placed on a slide. However, depending on sediment concentration, one additional drop of saline was added before examination for the purpose of detecting parasites by routine microscopy (Carvalho et al., 2015).

\section{Ethical Aspects}

This study was approved by the ethics committee of the city of Pedreira, SP, more precisely through the Departments of Health and Continuing Education (Process Number 1046/15). After obtaining all diagnostic results, the parasitized infant population received treatment based on specific medication, which was provided by the Health Centers of the city of Pedreira, SP.

\section{Statistical Analysis}

Statistical frequency of the results was defined as the number of existing cases occurring during the observation period and was presented as percentage. The chi-square test was used to verify association between parasitism and contact with pets.

\section{RESULTS}

Stool samples from 737 individuals were examined and 342 (46.4\%) of the children were infected with helminths and protozoa of the intestinal tract. Monoparasitism was detected in $194(26.3 \%)$ and polyparasitism in 148 (20.1\%) school children (Table 1). 
Table 1. Frequency (\%) of polyparasitism found in 737 school children from the city of Pedreira, SP.

\begin{tabular}{lcc}
\hline Polyparasitism & $\mathrm{n}$ & $(\%)$ \\
\hline 2 parasitic species & 91 & 61.5 \\
3 parasitic species & 46 & 31.1 \\
4 or more parasitic species & 11 & 7.4 \\
Total & 148 & 100.0 \\
\hline
\end{tabular}

The frequency values expressed in percentual of each species in 342 infected school children are shown in Table 2. Unlike specific technical procedures, the TF-Test technique shows good image quality with a different coloring (light green) and transparent vacuole (Figure $2 \mathrm{~A}$ ) in the parasite structures of Blastocystis spp., according to studies of Carvalho et al. (2015) and Rebolla et al. (2016). It is worth mentioning that, differently from the TF-Test technique, the structure of this parasite shows brown coloration when processed by conventional parasitological techniques (Figure $2 \mathrm{~B}$ ).

Table 2. Parasites and commensals distribution among positive children $(n=342)$ from the city of Pedreira, SP.

\begin{tabular}{lcc}
\hline Parasites & Children & Frequency* \\
\hline Protozoa & $\mathrm{n}$ & $(\%)$ \\
Blastocystis spp. & 238 & 69.6 \\
Entamoeba coli & 103 & 30.1 \\
Endolimax nana & 96 & 28.1 \\
Giardia duodenalis & 55 & 16.1 \\
Entamoeba histolytica/E. dispar & 21 & 6.1 \\
Iodamoeba bütschlii & 14 & 4.1 \\
Helminths & $\mathrm{n}$ & $(\%)$ \\
Ascaris lumbricoides & 13 & 3.8 \\
Enterobius vermicularis & 8 & 2.3 \\
Strongyloides stercoralis & 4 & 1.2 \\
Trichuris trichiura & 3 & 0.9 \\
Hookworms & 2 & 0.6 \\
\hline
\end{tabular}

* The values were calculated considering the polyparasitism cases in the infected children 


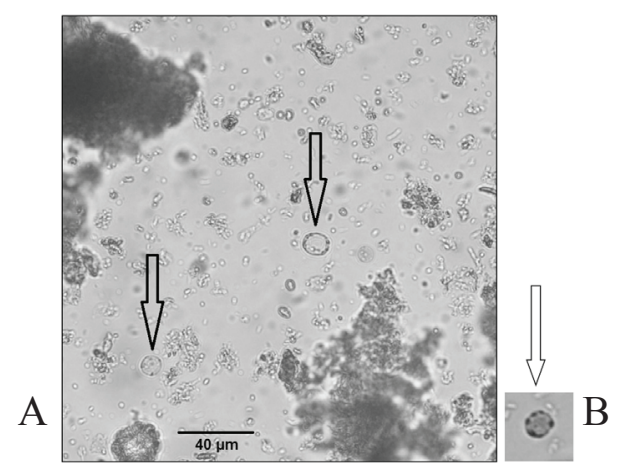

Figure 2. Blastocystis spp. vacuolar structures, according to the arrows. (Image: Visual Computing Laboratory in Biomedicine and Health, Institute of Computer Science, University of Campinas - UNICAMP)

Of the $342(100 \%)$ infected children, $310(90.6 \%)$ lived on the far outskirts of the city of Pedreira, SP, exceptionally with satisfactory sanitation. It is worth noting that, unlike the national average (41.9\%) in 2013, the mentioned city offered to its population $98.7 \%$ public sewer system, $1.3 \%$ cesspool sewage and $0.00 \%$ open sewage (Brasil, 2017). This city excellent condition of sanitation, confirms the great adaptation to the urban environment of protozoa groups, particularly in relation to helminths.

According to data obtained through questionnaires sent to the children's parents, it was possible to detect epidemiological risk factors for infection by intestinal parasites in infected children as shown in Figure 3. The statistical analysis to detect association among the risk factors variables and Blastocystis spp infection allowed the determination that the contact with pets is a significant risk factor $(\mathrm{p}<0.0001)$ (Table 3$)$.

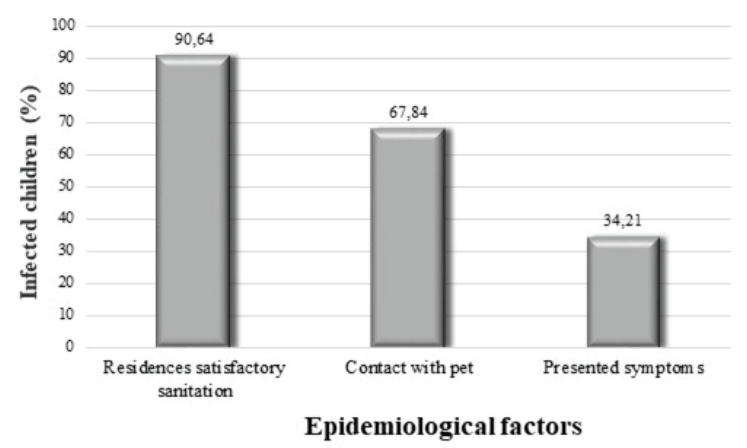

Figure 3. Epidemiological risk factors for infection by intestinal parasites in children of an urban region in the city of Pedreira, SP. 
Table 3. Frequency (\%) of parasitism in school children according to contact with pets, in the city of Pedreira, SP.

\begin{tabular}{|c|c|c|c|c|}
\hline \multirow{3}{*}{ Parasitism in children } & \multicolumn{4}{|c|}{ Contact with pets } \\
\hline & \multicolumn{2}{|c|}{ Present } & \multicolumn{2}{|c|}{ Absent } \\
\hline & $\mathrm{n}$ & $(\%)$ & $\mathrm{n}$ & $(\%)$ \\
\hline Monoparasitism & 98 & 50.5 & 96 & 49.5 \\
\hline Polyparasitism & 134 & 90.5 & 14 & 9.5 \\
\hline Total & 232 & 67.8 & 110 & 32.2 \\
\hline
\end{tabular}

Chi-square test $(\mathrm{p}<0,0001)$

Due to high intensity of the children parasitic infection, in accordance to reports from their parents, before medication treatment practiced by the health agency of the city of Pedreira, SP, 117 (34.2\%) had clinical symptomatology such as diarrhea, abdominal pain, vomiting, fatigue, body aches, absence of hunger with consequent malnutrition and weight loss. Of these symptomatic school children, 44 (12.9\%) had Blastocystis spp monoparasitism.

\section{DISCUSSION}

In conformity to the results of this study, there has been a predominance of protozoa in relation to intestinal helminths in the analyzed children population (Biscegli et al., 2008; Belo et al., 2012; Fonseca et al., 2014; Silva et al., 2016). These data corroborate several studies that have shown a higher protozoa infection prevalence in humans, especially in the peripheries of different urbanized regions of Brazil and other countries (Carvalho et al., 2006; Menezes et al., 2008; GonzálezMoreno et al., 2010; Silva et al.,2016; Yilmaz et al., 2012; Carvalho et al., 2015; Rebolla et al., 2016).

In addition, the literature has reported that in crowded places, especially where there is interpersonal contact, high rates of parasitic infections are expected, as it was found in this study, in which $46.4 \%$ (342/737) of the children were affected by one or more enteric parasite species (Carvalho et al., 2006, González-Moreno et al., 2010; Silva et al., 2016; Laodim et al., 2012). Furthermore, a high number (148) of children with multiple parasitic infections was found, and in fact, 57 individual cases had infections ranging from three to five parasite species. Certainly, choosing a parasitological technique of high diagnostic efficacy (TF-Test) has helped to detect more positive cases, in accordance with other studies that also demonstrated the high occurrence of individuals with polyparasitism, in contrast to other conventional techniques and/or commercial kits (Gomes et al., 2004; Carvalho et al., 2015; Coelho et al., 2015; Rebolla et al., 2016; Inácio et al., 2016). 
Of the 117 children with symptoms that have stopped going to schools on different days, 44 had monoparasitism by Blastocystis spp. This enteric parasite pathogenicity is subject of discussion among authors, given that existing studies are controversial with respect to its ability to cause disease in humans (Laodim et al., 2012, Pipatsatitpong et al., 2012, Rebolla et al., 2016; Lepczyńska, et al., 2017). However, some reports suggest that, especially in individuals infected only by this parasite added with symptoms, without the presence of another etiological agent, such as, virus or bacterium, Blastocystis may be considered as a potential causative pathogen to the specific disorder (Nagel et al., 2012; Pipatsatitpong et al., 2012; Poirier et al., 2012; Rebolla et al., 2016) being even mentioned by some authors as an emerging parasite (Tan et al., 2010; Melo et al., 2017).

In the present study Blastocystis spp was detected in $69.6 \%$ of the evaluated positive samples (Table 2). These results are similar to those found by Carvalho et al. (2015) and Rebolla et al. (2016), whose studies demonstrated frequencies of $27.3 \%$ and $86.6 \%$, respectively. However, unlike the current study, these authors studied human populations of urban regions with poor sanitary conditions. In areas with the same poor sanitary conditions, other authors also showed greater positivity of this parasite in human stool, compared to other parasitic species (Tan et al., 2010; Pipatsatitpong et al., 2012; Poirier et al., 2012; Yilmaz et al.,2012; Melo et al., 2017).

A high number of parasitic structures were detected in the children with positive diagnosis. These results confirm the values described in a compilation of two epidemiological studies regarding students in other Brazilian cities, especially for Blastocystis spp., E. coli, G. duodenalis and A. lumbricoides (Pedraza et al., 2014; Carvalho et al., 2015; Melo et al., 2010).

Besides a possible life cycle adaptation of these eukaryotes to urban centers, which some authors suggest as a "mark of the current urban parasitism", it is possible that the zoonotic process is working to encourage this situation. Given the numbers detected in this study, we observed that most of the parasitized children $(67.8 \%)$ had close contact with pets, such as dog and cat, with a significant association of parasitism variables between children and these animals $(\mathrm{p}<0,0001)$. The literature suggests there is a significant association in Blastocystis transmission between humans and domestic animals, being a relationship of fundamental contribution to high incidence of parasitism, as this organism may be identified in a wide range of vertebrate animals (Gomes et al., 2013; Tan et al., 2010; Nagel et al., 2012; Melo et al., 2017).

Therefore, perhaps there is the need for repeated parasitological examination of school children stool, especially due to the intermittency of elimination in the stool of different parasitic species, which can extend for more than ten days, leading to misdiagnosis (Garcia, 2009; Laodim et al., 2012; Carvalho et al., 2015)

Furthermore, in this study we considered health education, intended to inform about enteroparasite diseases in humans to the school children and their parents, in order to reduce risks of new parasitic infections in these young individuals through behavioral change. 


\section{ACKNOWLEDGMENTS}

Regarding the applicability of this study, the authors would like to acknowledge the unrestricted support of the city of Pedreira, SP, through the Departments of Health and Continuing Education; Writing Department/General Coordinator of University of Campinas (Portuguese acronym, UNICAMP); São Paulo Research Foundation (Portuguese acronym, FAPESP), and ImmunoCamp Science and Technology (Portuguese acronym, ImmunoCamp).

\section{REFERENCES}

1. Barreto ML, Genser B, Strina A Teixeira MG, Assis AM, Rego RF, Teles CA, Prado MS, Matos S, Alcântara-Neves NM, Cairncross S. Impact of a Citywide Sanitation Program in Northeast Brazil on Intestinal Parasites Infection in Young Children. Environ Health Perspect 18: 1637-1642, 2010.

2. Belo VS, Oliveira RB, Fernandes PC Nascimento BWL, Fernandes FV, Castro CLF, Santos WB, Silva ES. Factors Associated with Intestinal Parasitosis in a Population of Children and Adolescents. Rev Paul Pediatr 30: 195-201, 2012.

3. Biscegli TS, Romera J, Candido ECA, Binotto AL. Nutritional Status and Enteroparasitosis Prevalence Among Children Enrolled in a Day Care Center. Rev Paul Pediatr 27: 289-295, 2009.

4. Brasil. Ministério da Saúde. [Internet]. Sistema de Informação de Atenção Básica. Available at: http://www2.datasus.gov.br/SIAB/index.php?area=04 . Accessed at 17/10/17.

5. Brooker S. Estimating the global distribution and disease burden of intestinal nematode infections: adding up the numbers-a review. Int J Parasitol 40: 1137-1144, 2010.

6. Carvalho GL, Moreira LE, Pena JL, Marinho CC, Bahia MT, Machado-Coelho GL. A Comparative Study of the TF-Test, Kato-Katz, Hoffman-Pons-Janer, Willis and Baermann-Moraes Coprologic Methods for the Detection of Human Parasitosis. Mem Inst Oswaldo Cruz 107: 80-84, 2012.

7. Carvalho JB, Santos BM, Gomes JF Suzuki CTN, Hoshino-Shimizu S, Falcão AX, Pierucci JC, Matos LVS, Bresciani, KDS. TF-Test Modified: New Diagnostic Tool for Human Enteroparasitosis. J Clin Lab Anal 1: 1-8, 2015.

8. Carvalho TB, Carvalho LR, Mascarini L. Occurrence of Enteroparasites in Day Care Centers in Botucatu (São Paulo State, Brazil) with Emphasis on Cryptosporidium sp., Giardia duodenalis and Enterobius vermicularis. Rev Inst Med Trop S Paulo 48: 269-273, 2006.

9. Coelho WMD, Gomes JF, Falcão AX, dos Santos BM, Soares FA, Suzuki CTN, Amarante AFT, Bresciani KDS. Comparative Study of Five Techniques for the Diagnosis of Canine Gastrointestinal Parasites. Rev Bras Parasitol Vet 24: 223-226, 2015.

10. Fonseca JE, Carneiro M, Pena JL, Colosimo EA, da Silva NB, da Costa AGFC, Moreira LE, Cairncross S, Heller L. Reducing Occurrence of Giardia duodenalis in Children Living in Semiarid Regions: Impact of a Large Scale Rainwater Harvesting Initiative. PLoS Negl Trop Dis 8: e2943, 2014.

11. Garcia LS. Practical Guide to Diagnostic Parasitology. 2th ed. ASM Press, Washington (DC), 2009.

12. Gomes JF, Hoshino-Shimizu S, Dias LC, Araújo AJ, Castilho VL, Neves FA. Evaluation of a Novel kit (TF-Test) for the Diagnosis of Intestinal Parasitic Infections. J Clin Lab Anal 18: 132138, 2004.

13. Gomes JF, Suzuki CTN, Falcão AX, Shimizu SH, Coelho WMD, Cardia DFF, Inácio SV, Bresciani KDS. Advances in the Canine Coproparasitological Examination. In: Cohen KM, Diaz LR, org. Dogs; Domestication History, Behavior and Common Health Problems, 45 ed. Nova Science Publishers, New York, 2013. 
14. Gonzáles-Moreno O, Domingo L, Teixedor J, Gracenea M. Prevalence and Associated Factors of Intestinal Parasitisation: A Cross-sectional Study among Outpatients with Gastrointestinal Symptoms in Catalonia, Spain. Parasitol Res 108: 87-93, 2010.

15. Inácio SV, Gomes JF, Oliveira BCM, Falcão AX, Suzuki CTN, Santos BM, Aquino MCC, Ribeiro RSP, Assunção DM, Casemiro PAF, Meireles MV, Bresciani KDS. Validation of a New Technique to Detect Cryptosporidium spp. Oocysts in Bovine Feces. Prev Vet Med 134: 1-5, 2016.

16. Laodim P, Intapan PM, Sawanyawisuth K, Laummaunwai P, Maleewong W. A Hospital-Based Study of Epidemiological and Clinical Data on Blastocystis hominis infection. Foodborne Pathog Dis 9: 1077-1082, 2012.

17. Lawton AR, Cooper MD. Ontogeny of Immunity. In: Stiehm ER, ed. Immunologic Disorders in Infants and Children. WB Saunders, Philadelphia, 1989.

18. Lepczyńska M, Białkowska J, Dzika E, Piskorz-Ogórek K, Korycińska J. Blastocystis: How do Specific Diets and Human Gut Microbiota Affect its Development and Pathogenicity? Eur J Clin Microbiol Infect Dis 36: 1531-1540, 2017.

19. Melo EM, Ferraz FN, Aleixo DL. Importância do Estudo da Prevalência de Parasitos Intestinais de Crianças em Idade Escolar. Rev Saúde Biol 5: 43-47, 2010.

20. Melo GB, Paula FM, Malta FM, Maruta CW, Criado PR, Castilho VLP, Gonçalves EMN, Santo MCE, Gryschek RCB. Identification of Blastocystis subtypes in Clinical Stool Samples from São Paulo City, Brazil. Parasitol Open 3: 1-6, 2017.

21. Menezes AL, Lima VMP, Freitas MTS, Rocha MO, Silva EF, Dolabella SS. Prevalence of Intestinal Parasites in Children from Public Daycare Centers in the City of Belo Horizonte, Minas Gerais, Brazil. Rev Inst Med Trop S Paulo 50: 57-59, 2008.

22. Nagel R, Cuttell L, Stensvold CR, Mills PC, Bielefeldt-Ohmann H, Traub R J. Blastocystis Subtypes in Symptomatic and Asymptomatic Family Members and Pets and Response to Therapy. Intern Med J 42: 1187-1195, 2012.

23. Oberhelman AR, Guerrero EF, Fernadez ML Silo M, Mercado D, Comiskey N, Ihenacho G, Mera R. Correlations between Intestinal Parasitosis, Physical Growth and Psychomotor Development among Infants and Children from Rural Nicaragua. Am J Trop Med Hyg 58: 470-475, 1998.

24. Pedraza DF, Queiroz D, Sales MC. Doenças Infecciosas em Crianças Pré-Escolares Brasileiras Assistidas em Creches. Cienc Saúde Coletiva 19: 511-528, 2014.

25. Pipatsatitpong D, Rangsin R, Leelayoova S, Naaglor T, Mungthin M. Incidence and Risk Factors of Blastocystis Infection in an Orphanage in Bangkok, Thailand. Parasit Vectors 14: 37, 2012.

26. Poirier, P, Wawrzyniak I, Vivarés CP, Delbac F, El Alaoui H. New Insights into Blastocystis spp.: A Potential Link with Irritable Bowel Syndrome. PLoS Pathog. 8: e1002545, 2012.

27. Rebolla MF, Silva EM, Gomes JF, Falcão AX, Rebolla MVF, Franco RMB. High Prevalence of Blastocystis spp. Infection in Children and Staff Members Attending Public Urban Schools in São Paulo State, Brazil. Rev Inst Med Trop São Paulo 58: 31, 2016.

28. Silva JB, Bossolani GDP, Piva C, Dias GBM, Gomes JF, Rossoni DF, Mota LT, Toledo MJO. Spatial Distribution of Intestinal Parasitic Infections in a Kaingáng Indigenous Village from Southern Brazil. Int J Environ H Res 26: 578-588, 2016.

29. Stensvold CR, Clark CG. Current status of Blastocystis: A personal view. Parasitol Int 6: 65, 2016.

30. Tan KS, Mirza H, Teo JD, Wu B, Macary PA. Current views on the Clinical Relevance of Blastocystis spp. CInfect Diseases R 12: 28-35, 2010.

31. Yilmaz H, Tas-Cengiz Z, Ceylan A, Ekici A. The Distribution of Intestinal Parasites in People Admitted to the Yüzüncü Y1l University Parasitology Laboratory of Health Research and Training Hospital, in 2009. Turkiye Parazitol Derg 36: 105-108, 2012. 